\title{
Mapping of a Quantitative Trait Locus for Blood Pressure on Rat Chromosome 2
}

\author{
Alan Y. Deng, Howard Dene, and John P. Rapp \\ Department of Physiology and Molecular Medicine, Medical College of Ohio, Toledo, Ohio 43699
}

\begin{abstract}
A genetic map for rat chromosome 2 that includes five candidate genes for blood pressure regulation was constructed in a region containing a quantitative trait locus (QTL) for blood pressure. Two $F_{2}$ populations of male rats raised on high salt $(8 \% \mathrm{NaCl})$ diet from weaning were studied: $F_{2}($ WKY $\times S)$, derived from a cross of Dahl salt-sensitive rats (S) and Wistar-Kyoto rats (WKY); and $F_{2}(M N S \times S)$, derived from a cross of $S$ rats and Milan normotensive strain (MNS). In both populations a blood pressure QTL was localized between $\mathrm{Na}^{+}, \mathrm{K}^{+}$-ATPase $\alpha 1$ isoform and calmodulin-dependent protein kinase II-delta loci. The LOD score for existence of this blood pressure QTL based on the combined populations $(n=330)$ was 5.66 and accounted for $9.2 \%$ of the total variance and $26 \%$ of the genetic variance. (J. Clin. Invest. 1994. 94:431-436.) Key words: Dahl saltsensitive rat $\cdot \mathrm{Na}^{+}, \mathrm{K}^{+}$-ATPase $\alpha 1 \cdot$ interval mapping • quantitative trait locus $\bullet$ hypertension
\end{abstract}

\section{Introduction}

The identification of the individual loci influencing blood pressure in the rat is greatly facilitated by the advent of molecular genetics, although the rat genetic map is poorly developed compared with the mouse and human maps. Several individual loci cosegregating with blood pressure have been found in various rat models of hypertension using either the candidate gene approach or random genome scanning (1-12). Neither approach definitively identifies a locus causing blood pressure differences but only identifies a chromosomal region in which a quantitative trait locus (QTL) ${ }^{1}$ for blood pressure is statistically likely to occur. Further genetic verification of the existence of a QTL

Address correspondence to Alan Y. Deng, Ph.D., Department of Physiology and Molecular Medicine, Health Science Building, Room 320, Medical College of Ohio, P.O. Box 10008, Toledo, OH 43699.

Received for publication 4 October 1993 and in revised form 5 April 1994.

1. Abbreviations used in this paper: $A T 1 B$, angiotensin II receptor $\mathrm{AT} 1 \mathrm{~b}$; $C A M K$, calmodulin-dependent protein kinase II-delta; $C P B$, carboxy peptidase B; $D 2 N 35$, an anonymous locus; $F G G$, fibrinogen gamma; $G C A$, guanylyl cyclase $\mathrm{A} /$ atrial natriuretic peptide receptor $\mathrm{A} ; H S D$,

J. Clin. Invest.

(c) The American Society for Clinical Investigation, Inc. 0021-9738/94/07/0431/06 \$2.00

Volume 94, July 1994, 431-436 and "positional cloning" $(13,14)$ of the definitive QTL will ultimately depend on the development of congenic strains carrying the QTL-containing region in progressively smaller and smaller chromosomal fragments. This can only be accomplished if a dense genetic map is available in the chromosomal region of interest.

Our attention was initially directed to a region of rat chromosome 2 by our observation (6) that the candidate gene guanylyl cyclase A/atrial natriuretic peptide receptor A (GCA) on chromosome 2 cosegregates with blood pressure. As it turns out, GCA is at the edge of the region likely to contain the QTL. The present work builds on existing linkage groups and genetic maps for rat chromosome 2 (15-17). We localize a QTL for blood pressure by genotyping 10 informative markers on chromosome 2 in large segregating $F_{2}$ populations derived by crossing Dahl salt-sensitive rats with various control strains.

\section{Methods}

Animal procedures. Inbred Dahl salt-sensitive (SS/Jr) rats (18) were used and will be referred to hereafter as $S$ rats. Milan normotensive strain (MNS) (19) rats were obtained from Vincent Gattone (University of Kansas) who had imported them from their founder, Giuseppe Bianchi (University of Milan, Italy). (The strain is currently available from Dr. Carl Hansen, Veterinary Resources Division, National Institutes of Health, Bethesda, MD) Wistar-Kyoto rats (WKY/NHsd), referred to hereafter as WKY, were obtained from Harlan Sprague Dawley, Inc. (Indianapolis, IN).

Two $F_{2}$ populations were produced. The $F_{2}(W K Y \times S)$ population of 159 rats was produced by crossing WKY females with $S$ males to produce $F_{1}$ rats, and then intercrossing $F_{1} \times F_{1}$ to produce $F_{2}$. The $F_{2}$ $($ MNS $\times S$ ) population of 171 rats was produced by crossing MNS males with $S$ females to produce $F_{1}$, which were intercrossed to produce $F_{2}$. These are the same populations used previously (6).

Only male $F_{2}$ rats were studied. $F_{2}$ rats were weaned at $30 \mathrm{~d}$ of age and placed on high salt $(8 \% \mathrm{NaCl})$ diet (diet TD 82050; Teklad Premier Laboratory Diets, Madison, WI) at $37 \mathrm{~d}$ of age. The populations were maintained on high salt diet until the rats with the highest blood pressure had reached $>200 \mathrm{mmHg}$. This took 12 wk on high salt diet for $F_{2}$ $(W K Y \times S)$ and $10 \mathrm{wk}$ for $\mathrm{F}_{2}(\mathrm{MNS} \times \mathrm{S})$, at which point the blood pressures of the rats were studied intensively during a 7-10-d period. Blood pressure was taken by the tail cuff method $(20,21)$ under light ether anesthesia with the rats warmed to $28^{\circ} \mathrm{C}$. At least three consecutive consistent readings were taken during three separate sessions separated

$3 \beta$-hydroxysteroid dehydrogenase/delta 5 isomerase; MNS, Milan normotensive strain; NAK $\alpha 1, \mathrm{Na}^{+}, \mathrm{K}^{+}$-ATPase $\alpha 1 ; N E P$, neutral endopeptidase/enkephalinase (EC 3.4.24.11); $P R L R$, prolactin receptor; QTL, quantitative trait locus; $R$, inbred Dahl salt-resistant rats (SR/ $\mathrm{Jr})$; S, inbred Dahl salt-sensitive rats $(\mathrm{SS} / \mathrm{Jr})$; SSR, simple sequence repeats; WKY, Wistar-Kyoto rats. 
Table I. Primer Sets for PCR around SSR for Loci on Rat Chromosome 2

\begin{tabular}{|c|c|c|c|c|}
\hline Locus & $\begin{array}{c}\text { GenBank } \\
\text { accession number }\end{array}$ & Primers $\left(5^{\prime} \rightarrow 3^{\prime}\right)$ & Expected size (bp) & Relative size of PCR products \\
\hline$D 2 N 35$ & M98802 & $\begin{array}{l}\text { CTGTCTAGTCAAGTGTCTGTGC } \\
\text { CCCTAACCATAGTGGAAATCC }\end{array}$ & 213 & MNS $>$ S $>$ WKY \\
\hline CAMK & $\mathrm{J} 05072$ & $\begin{array}{l}\text { CTCCGACAAGAAAACTCCGCAA } \\
\text { CAGGATCACACCAGGAACTGAA }\end{array}$ & 255 & $\mathrm{MNS}=\mathrm{WKY}>\mathrm{S}$ \\
\hline$N A K \alpha 1$ & x53234 & $\begin{array}{l}\text { AACCCAGTGGTAGCTTCCATCC } \\
\text { TACTTGTCTCGTCCAACCTACAG }\end{array}$ & 187 & MNS $>$ WKY $>$ S \\
\hline$H S D$ & Ṃ̣67465 & $\begin{array}{l}\text { ACTAGAGTCAGGAGGCAAAACC } \\
\text { ACCCTATGTGAAATGGTGATGC }\end{array}$ & 217 & WKY $>$ MNS $>$ S \\
\hline$G C A$ & J05677 & $\begin{array}{l}\text { CCCTGCGTGTTCATTCATGTGG } \\
\text { ATCAGATTCCTGAAGGCATCCG }\end{array}$ & 286 & MNS $>$ WKY $>$ S \\
\hline$F G G$ & K01337 & $\begin{array}{l}\text { CAGTAAGTGCTCTTCAGAAGCC } \\
\text { TGTACTGCTGTGGGAGAAAAA }\end{array}$ & 136 & $\mathrm{MNS}=\mathrm{WKY}>\mathrm{S}$ \\
\hline$N E P^{*}$ & U01225 & $\begin{array}{l}\text { GGGCACTCATAGATGAAGATGG } \\
\text { CCGTCCTTTTAATGATC }\end{array}$ & 333 & $\mathrm{~S}>\mathrm{WKY}=\mathrm{MNS}$ \\
\hline$N E P^{*}$ & U01226 & $\begin{array}{l}\text { AAGGCTCCAAACTACAAACCCG } \\
\text { TTGGCTCAGTCAGGATCTAAGG }\end{array}$ & 241 & $\mathrm{R}>\mathrm{S}=\mathrm{MNS}=\mathrm{WKY}$ \\
\hline$C P B$ & M23951 & $\begin{array}{l}\text { TCCCTTCTAAGCATACTTTCCA } \\
\text { TGAAGAGACAACCCTAGAGACC }\end{array}$ & 149 & WKY $>$ MNS $>$ S \\
\hline$A T 1 B^{*}$ & U01223 & $\begin{array}{l}\text { CTCTCCATCCACAAACATCC } \\
\text { ACTGTCCTGTCTGACTAG }\end{array}$ & 192 & $\mathrm{~S}>\mathrm{MNS}=\mathrm{WKY}$ \\
\hline$A T 1 B^{*}$ & U01224 & $\begin{array}{l}\text { TTTCTGAACCAACCAACC } \\
\text { AAGTGGTCCTCTAACCTG }\end{array}$ & 276 & $\mathrm{~S}>\mathrm{MNS}=\mathrm{WKY}$ \\
\hline$P R L R$ & M19304 & $\begin{array}{l}\text { ATCTTGATCCCTCAGTCTCACG } \\
\text { CAAGCCCAGAAAAGCATGAAGC }\end{array}$ & 209 & $\mathbf{W K Y}=\mathbf{M N S}>\mathbf{S}$ \\
\hline
\end{tabular}

* Indicates newly developed and newly assigned loci. The two primer sets for ATIB and NEP are for different SSR at these loci.

by $2 \mathrm{~d}$, and these three separate session pressures were averaged ais the final blood pressure.

Genotyping. Rats were killed by an overdose of sodium pentobarbital, and pieces of liver were frozen at $-70^{\circ} \mathrm{C}$. Liver DNA was extracted by the method of Blin and Stafford (22).

All genotyping was done with DNA amplification by PCR around simple sequence repeats (SSR) (so-called microsatellites). The methods were given in detail previously (6). Table I gives the primer sets used for PCR at each locus. Although the selection of 7 out of the 10 loci (an anonymous locus [D2N35], calmodulin-dependent protein kinase II-delta [CAMK], $\mathrm{Na}^{+}, \mathrm{K}^{+}$-ATPase $\alpha 1$ [NAK $\left.\alpha 1\right], 3 \beta$-hydroxysteroid dehydrogenase/delta 5 isomerase $[H S D]$, fibrinogen gamma $[F G G]$, carboxy peptidase $\mathrm{B}[C P B]$, and prolactin receptor $[P R L R])$ used is based on previous chromosomal localization and mapping data (1517 ), all of the primers, except $H S D(17), N A K \alpha l(16)$, and $F G G(15)$, were redesigned based on GenBank sequences. GCA primers were those we used previously (6) based on sequence data for GCA in the literature (23). Primers for neutral endopeptidase/enkephalinase (NEP, EC 3.4.24.11) and angiotensin II receptor AT1b (AT1B) are based on our new sequence data.

Developing new SSR markers. A cDNA probe of 1,340 bp for NEP was obtained by PCR from a cDNA lambda gt11 library made from $S$ kidneys. The primers used for amplification were based on a published sequence (24) and consisted of a forward primer of 5'-CAAATATGCTTGTGGAGGCTGG-3' and a reverse primer of 5'-GTCCTGGAGGTTCATAATGG-3'. A genomic DNA probe of 241 bp for ATIB was based on a published sequence (25) and was amplified by PCR from rat genomic DNA with a pair of primers that amplified a region specific for $A T I B$ as opposed to another angiotensin II receptor, ATIA. The primers were forward 5' ${ }^{\prime}$-ACTACCGAGGAGTGTTCAACC-3' and reverse $5^{\prime}$-TACGTTTCTGCTAGTACACC-3'. After PCR amplification, these probes were separated on a $1.5 \%$ agarose gel, excised, purified using glass milk (BIO 101, Inc., La Jolla, CA), subcloned into a PCR TA II vector (Invitrogen, San Diego, CA), and sequenced using a Sequenase kit (US Biochemical, Cleveland, $\mathrm{OH}$ ) to confirm that the sequence of the products obtained agreed with the published sequences.

For genomic library screening the NEP or $A T I B$ DNA probes were labeled using a random priming kit (Boehringer Mannheim, Indianapolis, IN), purified using a Bio-6 column (BIO-RAD, Melville, NY), and used to screen a rat genomic library made from Dahl salt-resistant rats in lambda phage GEM-11 (Promega Corp., Madison, WI). Standard procedures for growing phage, filter lifting onto nylon filters (Schleicher and Schuell, Inc., Keene, NH), treatment of DNA on the filters, and hybridization were used (26).

Phage DNA from purified clones containing NEP or AT1B was prepared after growth in NZCYM liquid medium by a standard method (26). The cloned DNA inserts were cut with a series of restriction enzymes that cut the vector only once. The digested fragments were then separated on a $1 \%$ agarose gel, transferred to a sheet of DuralonUV membrane (Stratagene, La Jolla, CA), fixed by UV cross-linking, and probed with a mixture of $(\mathrm{CA})_{15}$ and $(\mathrm{CT})_{15}$ oligonucleotides that were labeled with $\left[\gamma-{ }^{32} \mathrm{P}\right]$ ATP and T4 polynucleotide kinase and purified on a Sep-Pak $\mathrm{C}_{18}$ column (Waters Associates, Milford, MA).

The genomic fragments recognized by the $(\mathrm{CA})_{15}$ or $(\mathrm{CT})_{15}$ oligonucleotides were then subcloned into a plasmid vector pT7T3 18U (Pharmacia LKB Biotechnology, Piscataway, NJ). The subcloned genomic fragments containing $(\mathrm{CA})_{\mathrm{n}}$ or $(\mathrm{CT})_{\mathrm{n}}$ for either $N E P$ or $A T 1 B$ were repeatedly digested with different restriction enzymes followed by another round of subcloning until the fragment containing the repeated elements was $<1 \mathrm{~kb}$. These clones were then sequenced, and the sequence information was used to design primers that would amplify a product containing the $(C A)_{n}$ or $(C T)_{n}$ repeated elements.

Statistical analysis. Analysis of variance was done using SPSS programs (SPSS Inc., Chicago, IL). Oligonucleotide primers for PCR were 


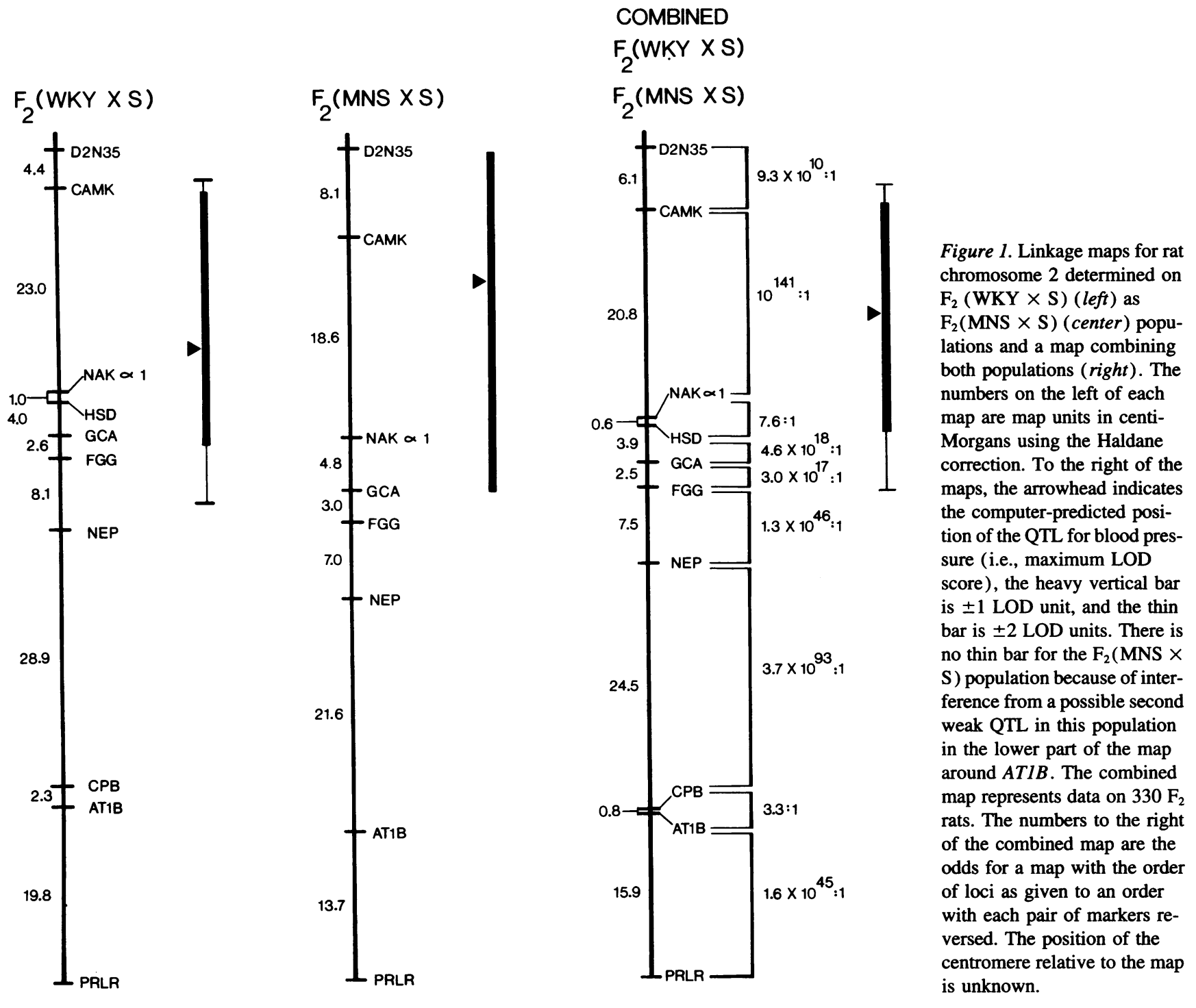

designed using the Primer Detective Program (Clontech, Palo Alto, CA). Linkage maps and QTL localization were done with MAPMAKER/QTL programs $(27,28)$ for IBM-compatible personal computers available from Eric Lander (Whitehead Institute, Cambridge, MA).

In QTL analysis of blood pressure in the rat, Jacob et al. (5) suggested that an LOD score of 3 should be set as the significance level to reasonably establish the existence of a QTL. Based on their analysis (5), we feel that it is also reasonable to further investigate loci with LOD scores between 2 and 3 by trying to find more flanking markers and/or to increase the size of the population.

\section{Results}

Fig. 1 gives the linkage maps for rat chromosome 2 generated for the $F_{2}(W K Y \times S)$ and $F_{2}(M N S \times S)$ populations and a composite map combining both populations. Blood pressure data by genotype and analysis of variance data are given for the chromosome 2 loci in Table II for $F_{2}(W K Y \times S)$ and Table III for $F_{2}(M N S \times S)$. In Table II for the $F_{2}(W K Y \times S)$ population of 159 rats, it is obvious that the blood pressure effect cosegregating with the chromosomal markers between

$D 2 N 35$ and $N E P$ is at a maximum at the $N A K \alpha 1$ locus and falls off substantially on either side of $N A K \alpha 1$. The MAPMAKER/ QTL program localizes the QTL (Fig. 1) close to $N A K \alpha 1$, between $N A K \alpha 1$ and $C A M K$ with a maximum LOD score of 3.42. The QTL accounted for $10.9 \%$ of the total variance and $\sim 31 \%$ of the genetic variance.

In Table III for the $F_{2}(M N S \times S)$ population of 171 rats, the blood pressure effect of the chromosomal region from $D 2 N 35$ to $N E P$ is less pronounced than for the $\mathrm{F}_{2}(\mathrm{WKY} \times \mathrm{S})$ population. The maximum LOD score was 2.62 which localized the QTL closer to CAMK than NAK $\alpha 1$ (Fig. 1). The QTL accounted for $8 \%$ of the total variance and $\sim 23 \%$ of the genetic variance. A QTL on chromosome 10 in the region of angiotensin-converting enzyme was previously shown (6) also to cosegregate with blood pressure in the $F_{2}(M N S \times S)$ population. The two QTL on chromosome 10 and 2 together accounted for $19 \%$ of the total variance (or $\sim 55 \%$ of the genetic variance) as estimated by using the MAPMAKER/QTL program. The blood pressure effect and statistical significance decrease going down the loci as listed in Table III to NEP and then increase again toward the bottom of the table in the region around $A T 1 B$. The maxi- 
Table II. Systolic Blood Pressure by Genotype for Loci on Rat Chromosome 2 in the $F_{2}(W K Y \times S)$ Population Fed High Salt Diet

\begin{tabular}{|c|c|c|c|c|c|}
\hline \multirow[b]{2}{*}{ Locus } & \multicolumn{3}{|c|}{ Blood pressure by genotype } & \multirow[b]{2}{*}{ D } & \multirow[b]{2}{*}{ Probability one-way ANOVA } \\
\hline & $w W$ & ws & sS & & \\
\hline D2N35 & $169.0 \pm 4.21$ & $172.8 \pm 2.33$ & $181.6 \pm 4.31$ & +12.6 & 0.055 \\
\hline$n$ & 44 & 75 & 40 & & \\
\hline CAMK & $165.8 \pm 3.81$ & $173.6 \pm 2.57$ & $183.4 \pm 4.02$ & +17.6 & 0.0038 \\
\hline$n$ & 44 & 73 & 42 & & \\
\hline$N A K \alpha 1$ & $166.0 \pm 3.28$ & $173.1 \pm 2.44$ & $186.7 \pm 4.86$ & +20.7 & 0.0005 \\
\hline$n$ & 49 & 74 & 36 & & \\
\hline$H S D$ & $166.8 \pm 3.37$ & $172.3 \pm 2.45$ & $186.5 \pm 4.73$ & +19.7 & 0.0007 \\
\hline$n$ & 47 & 75 & 37 & & \\
\hline$G C A$ & $167.6 \pm 3.35$ & $172.3 \pm 2.44$ & $185.3 \pm 4.81$ & +17.7 & 0.0027 \\
\hline$n$ & 48 & 73 & 38 & & \\
\hline$F G G$ & $167.8 \pm 3.39$ & $173.2 \pm 2.60$ & $183.6 \pm 4.69$ & +15.8 & 0.014 \\
\hline$n$ & 46 & 77 & 36 & & \\
\hline$N E P$ & $169.4 \pm 3.47$ & $174.0 \pm 2.56$ & $179.9 \pm 5.11$ & +10.5 & 0.18 \\
\hline$n$ & 44 & 82 & 33 & & \\
\hline$C P B$ & $170.4 \pm 3.90$ & $174.2 \pm 2.65$ & $176.3 \pm 4.22$ & +5.9 & 0.60 \\
\hline$n$ & 32 & 87 & 40 & & \\
\hline$A T 1 B$ & $170.7 \pm 3.83$ & $174.2 \pm 2.63$ & $176.3 \pm 4.39$ & +5.6 & 0.63 \\
\hline$n$ & 33 & 88 & 38 & & \\
\hline$P R L R$ & $171.0 \pm 4.77$ & $173.7 \pm 2.41$ & $176.7 \pm 4.39$ & +5.7 & 0.64 \\
\hline$n$ & 29 & 89 & 41 & & \\
\hline
\end{tabular}

Blood pressure data are means $\pm \mathrm{SE}$ in millimeters of mercury for each genotype. $W$, Allele for WKY rats; $S$, allele for $\mathrm{S}$ rats; D, blood pressure differences homozygous $S S$ minus homozygous $W W ; n$, number of rats in each genotypic class.

mum LOD score in this region is at $A T 1 B$ and equals 1.83 .

The population blood pressure means for the $\mathrm{F}_{2}(\mathrm{WKY} \times \mathrm{S})$ and $F_{2}(\mathrm{MNS} \times \mathrm{S})$ populations were 174.0 and $173.9 \mathrm{mmHg}$, respectively. The two populations were combined, and QTL interval mapping was performed on the combined data ( $n$ $=330$ ). The combined data gave an LOD score of 5.66 for the existence of a blood pressure QTL at about the midpoint between $N A K \alpha 1$ and $C A M K$ (Fig. 1). In the combined analysis, the QTL accounted for $9.2 \%$ of the total variance and $\sim 26 \%$ of the genetic variance.

The blood pressure distributions of both $F_{2}$ populations were skewed to the right. A logarithmic transformation partially corrects for this. Analysis on the log of blood pressure did not alter any of the conclusions given above. Use of a nonparametric test (Kruskal-Wallis) in place of the one-way analysis of variance in Tables II and III also did not alter the conclusions.

\section{Discussion}

The data show that a QTL for blood pressure response to high salt diet is located on rat chromosome 2 between the $N A K \alpha 1$ and $C A M K$ loci. Essentially, the same localization was obtained in both the $F_{2}(W K Y \times S)$ and $F_{2}(M N S \times S)$ populations, which strengthens the result. The region likely to contain the QTL spans about 30 centiMorgans (cM), which is too large to work with for positional cloning. Computer simulations suggest that QTL localization is dependent mainly on the size of the experiment and the magnitude of the effect of the QTL (29). The effect of the QTL is not under our control, and the size of these experiments (a total of 330 rats in the two populations) has reached a practical limit. Even with a population of $n$
$=1,000$ and a QTL of large effect, simulations show that QTL localization cannot be better than $10 \mathrm{cM}$ (29).

An obvious way to proceed for better QTL localization is to next produce a congenic strain with a large segment of chromosome to prove (or disprove) the existence of the QTL. Then from this a series of congenic substrains containing small overlapping regions of chromosome from the region now known to contain the QTL can be constructed. Regions transferred between strains containing the QTL should influence blood pressure, and those regions not containing the QTL should not influence blood pressure. Provided a dense genetic map is available allowing the manipulation of small regions, the QTL localization could be further narrowed to an even smaller chromosomal fragment. This should map the QTL to within 1-2 cM.

The data for the presence of a second blood pressure QTL on chromosome 2 near $A T 1 B$ in the $\mathrm{F}_{2}(\mathrm{MNS} \times \mathrm{S})$ population are merely suggestive. The significance levels associated with this region are too weak to establish the existence of a second QTL. It has, however, been reported (8) in an $F_{2}$ population derived from a cross of Lyon hypertensive and Lyon normotensive rats that systolic blood pressure (as well as pulse pressure) cosegregates highly significantly with $C P B$. $C P B$ is located very close to $A T 1 B$. The fact that there was clearly no evidence for a second QTL in the $\mathrm{F}_{2}(\mathrm{WKY} \times \mathrm{S})$ population at the $C P B$ $A T 1 B$ region can be explained by assuming that WKY and $S$ do not carry functionally contrasting alleles in this region. Alternatively, there may, in fact, be no QTL in this region.

It is of interest that there are several candidate genes for blood pressure regulation on rat chromosome 2 . These are $N A K \alpha 1, H S D, G C A, N E P$, and $A T 1 B$ with NAK $\alpha 1$ being the closest to the position of the maximum LOD score for the 


\begin{tabular}{|c|c|c|c|c|c|}
\hline \multirow[b]{2}{*}{ Locus } & \multicolumn{3}{|c|}{ Blood pressure by genotype } & \multirow[b]{2}{*}{$\mathbf{D}$} & \multirow{2}{*}{$\begin{array}{l}\text { Probability one- } \\
\text { way ANOVA }\end{array}$} \\
\hline & $M M$ & $M S$ & ss & & \\
\hline$D 2 N 35$ & $171.8 \pm 2.51$ & $171.5 \pm 2.18$ & $181.9 \pm 4.22$ & +10.1 & 0.032 \\
\hline$n$ & 45 & 89 & 37 & & \\
\hline CAMK & $169.0 \pm 2.24$ & $171.8 \pm 2.27$ & $182.9 \pm 3.86$ & +13.9 & 0.0031 \\
\hline$n$ & 48 & 79 & 44 & & \\
\hline$N A K \alpha 1$ & $168.1 \pm 2.48$ & $174.7 \pm 2.16$ & $180.3 \pm 4.53$ & +12.2 & 0.026 \\
\hline$n$ & 52 & 84 & 35 & & \\
\hline$H S D$ & Not tested & & & & \\
\hline$G C A$ & $168.2 \pm 2.57$ & $173.9 \pm 2.12$ & $181.0 \pm 4.41$ & +12.8 & 0.024 \\
\hline$n$ & 47 & 88 & 36 & & \\
\hline$F G G$ & $168.6 \pm 2.44$ & $174.1 \pm 2.15$ & $181.3 \pm 4.78$ & +12.7 & 0.028 \\
\hline$n$ & 51 & 88 & 32 & & \\
\hline$N E P$ & $168.8 \pm 2.60$ & $175.7 \pm 2.24$ & $176.4 \pm 4.14$ & +7.6 & 0.13 \\
\hline$n$ & 50 & 84 & 37 & & \\
\hline$C P B$ & Not tested & & & & \\
\hline$A T 1 B$ & $166.8 \pm 2.35$ & $177.6 \pm 2.30$ & $175.1 \pm 4.29$ & +8.3 & 0.014 \\
\hline$n$ & 52 & 87 & 32 & & \\
\hline PRLR & $168.1 \pm 2.32$ & $175.7 \pm 2.40$ & $178.6 \pm 4.16$ & +10.5 & 0.036 \\
\hline$n$ & 56 & 80 & 35 & & \\
\hline
\end{tabular}

Blood pressure data are means \pm SE in millimeters of mercury for each genotype. $M$, Allele from MNS rats; $S$, allele from $S$ rats; D, blood pressure difference homozygous $S S$ minus homozygous $M M ; n$, number of rats in each genotypic class.

QTL. Since sodium balance is generally thought to be intimately related to chronic regulation of blood pressure, any genes involved in sodium transport or regulation are obvious candidates for influencing blood pressure. Because various isoforms of NaK-ATPase are involved not only in sodium handling by the kidney but also in regulation of vascular smooth muscle tone and cardiac contractility, NaK-ATPase genes are candidates for influencing blood pressure. HSD could alter adrenal steroid production and could thereby affect blood pressure. Atrial natriuretic peptide is a hormone secreted from heart atria in response to blood volume expansion and causes the kidney to excrete sodium and water. Thus, GCA, one of the receptors for atrial natriuretic peptide, is potentially important in blood pressure regulation. NEP is a peptidase that is important in metabolizing atrial natriuretic peptide and has been a target of antihypertensive drug therapy. AT1B is a receptor for angiotensin II. Since the renin-angiotensin system is intimately involved in blood pressure regulation, $A T 1 B$ is an obvious candidate gene.

$N A K \alpha 1$ has been studied in segregating populations derived from a cross of Dahl S and Dahl salt-resistant $(R)$ rats. It did not cosegregate with blood pressure in this cross (30), indicating that $\mathrm{S}$ and $\mathrm{R}$ do not carry a functionally different blood pressure QTL in this region of chromosome 2. NAK $\alpha 1$ was thought to have a single base change in the coding region of $S$ and $R$ rats which would alter enzyme structure (31). This DNA variation, however, could not be confirmed and could be the result of a cloning artifact (32). NEP was also tested in an $F_{2}(R \times S)$ population and also did not cosegregate with blood pressure (Deng, A. Y., and J. P. Rapp, unpublished observations).

There is no reason to suppose that the region of rat chromosome 2 is unique with regard to the density of candidate genes for blood pressure regulation. On the contrary, it is our recent experience that many regions where blood pressure QTLs are found also contain multiple rational candidates and that the identity of the QTL could be none of the obvious candidates. A possible example of a failed candidate is the renin locus where alleles present in Dahl $S$ and $R$ rats cosegregate strongly with blood pressure in $F_{2}(3)$ and backcross populations (33) and in a duplicated $F_{2}$ population (34). There was, however, no DNA sequence difference in the coding or regulatory regions of $S$ and $R$ renin alleles (35), and there is no logical physiological correlate, since $S$ rats have low plasma and renal renin (36, 37 ), whereas high renin would make more sense as a cause of elevated blood pressure. An example of a possibly successful candidate is $11 \beta$-hydroxylase in Dahl $S$ and $R$ rats where there is a logical physiological correlate (altered steroidogenic pattern resulting in high production of the mildly hypertensinogenic steroid, 18-hydroxy-11-deoxycorticosterone) $(1,2,38)$, the alleles in $S$ and $R$ rats cosegregate with blood pressure $(1,12)$, and there are base changes in the coding region causing five amino acid substitutions $(12,39)$. In vitro production of chimeric $11 \beta$-hydroxylase genes between $S$ and $R$ was able to narrow the causative lesion to a subset of three of these five amino acid changes (39).

In summary the data clearly point to the existence of a blood pressure QTL between $N A K \alpha 1$ and $C A M K$ on rat chromosome 2 that accounts for $9.2 \%$ of the total variance and $26 \%$ of the genetic variance for rats on a high salt diet.

\section{Acknowledgments}

We thank Dr. Eric Lander for supplying the MAPMAKER/QTL programs; Dr. Mark Daly for help with running the programs; and Dr. Dwight Ginn for preparing the rat genomic library. 

Health.

This work was supported by grants from the National Institutes of

\section{References}

1. Rapp, J. P., and L. K. Dahl. 1972. Mendelian inheritance of 18- and $11 \beta$ steroid hydroxylase activities in the adrenals of rats genetically susceptible or resistant to hypertension. Endocrinology. 90:1435-1446.

2. Rapp, J. P., and L. K. Dahl. 1976. Mutant forms of cytochromic P-450 controlling both 18 - and $11 \beta$-steroid hydroxylation in the rat. Biochemistry. 15:1235-1242.

3. Rapp, J. P., S.-M. Wang, and H. Dene. 1989. A genetic polymorphism in the renin gene of Dahl rats cosegregates with blood pressure. Science (Wash DC). 243:542-544.

4. Hilbert, P., K. Lindpaintner, J. S. Beckmann, T. Serikawa, F. Soubrier, C. Dubay, P. Cartwright, B. De Gouyon, D. Julier, S. Takahasi, et al. 1991. Chromosomal mapping of two genetic loci associated with blood-pressure regulation in heredity hypertensive rats. Nature (Lond.). 353:521-529.

5. Jacob, H. J., K. Lindpaintner, S. E. Lincoln, K. Kusumi, R. K. Bunker, Y. Mao, D. Ganten, V. Dzau, and E. S. Lander. 1991. Genetic mapping of a gene causing hypertension in the stroke-prone spontaneously hypertensive rat. Cell. 67:213-224.

6. Deng, Y., and J. P. Rapp. 1992. Cosegregation of blood pressure with angiotensin converting enzyme and atrial natriuretic peptide receptor genes using Dahl salt-sensitive rats. Nature Genetics. 1:267-272.

7. Iwai, H., and T. Inagami. 1992. Identification of a candidate gene responsible for the high blood pressure of spontaneously hypertensive rats. J. Hypertens. 10:1155-1157.

8. Dubay, C., M. Vincent, N. J. Samani, P. Hilbert, M. A. Kaiser, J. Beressi, Y. Kotelevtsev, J. S. Bechmann, R. Soubrier, J. Sassard, and G. M. Lathrop. 1993. Genetic determinants of diastolic and pulse pressure map to different loci in Lyon hypertensive rats. Nature Genetics. 3:354-357.

9. Lindpaintner, K., P. Hilbert, D. Ganten, B. Nadal-Ginard, T. Inagami, and H. Iwai. 1993. Molecular genetics of the SA gene: cosegregation with hypertension and mapping to rat chromosome 1. J. Hypertens. 11:19-23.

10. Harris, E. L., H. Dene, and J. P. Rapp. 1993. SA gene and blood pressure cosegregation using Dahl salt-sensitive rats. Am. J. Hypertens. 6:330-334.

11. Samani, N. J., D. Lodwick, M. Vincent, C. Dubay, M. A. Kaiser, M. P. Kelly, M. Lo, J. Harris, J. Sassard, M. Lathrop, and J. D. Swales. 1993. A gene differentially expressed in the kidney of the spontaneously hypertensive rat cosegregates with increased blood pressure. J. Clin. Invest. 92:1099-1103.

12. Cicila, G. T., J. P. Rapp, J. M. Wang, E. St. Lezin, S. C. Ng, and T. W. Kurtz. 1993. Linkage of $11 \beta$-hydroxylase mutations with altered steroid biosynthesis and blood pressure in the Dahl rat. Nature Genetics. 3:346-353.

13. Collins, F. S. 1992. Positional cloning: let's not call it reverse anymore. Nature Genetics. 1:3-6.

14. Ballabio, A. 1993. The rise and fall of positional cloning. Nature Genetics. 3:277-279.

15. Serikawa, T., T. Kuramoto, P. Hilbert, M. Mori, J. Ramada, C. Dubay, K. Lindpainter, D. Ganten, J. Guenet, G. M. Lathrop, and J. S. Beckmann. 1992. Rat gene mapping using PCR-analyzed microsatellites. Genetics. 131:701-721.

16. Kunieda, T., E. Kobayashi, M. Tachibana, H. Ikadai, and T. Imamichi. 1992. Polymorphic microsatellite loci of the rat (Rattas norvegicus). Mamm Genome. 3:564-567.

17. Zha, H., R. L. Wilder, E. A. Goldmantz, J. M. Cash, L. J. Crofford, P. Mathern, and E. F. Remmers. 1993. Linkage map of 10 polymorphic markers on rat chromosome 2. Cytogenet. Cell Genet. 63:117-122.

18. Rapp, J. P., and H. Dene. 1985. Development and characteristics of inbred strains of Dahl salt-sensitive and salt-resistant rats. Hypertension (Dallas). 7:340349.

19. Bianchi, G., P. Ferrai, and B. R. Barker. 1984. Handbook of Hypertension. W. deJong, editor. Elsevier Science Publishing Co. Inc., New York. 328-349.

20. Friedman, M., and C. Freed. 1949. Microphonic manometer for indirect determination of systolic blood pressure in the rat. Proc. Soc. Exp. Biol. Med. 70:670-672.

21. Bunag, R. D., and J. Butterfield. 1982. Tail cuff blood pressure measurement without external preheating in awake rats. Hypertension (Dallas). 4:898903.

22. Blin, N., and D. W. Stafford. 1976. Isolation of high molecular weight DNA. Nucleic Acids Res. 3:2303-2308.

23. Yamaguchi, M., L. T. Rutledge, and D. L. Garbers. 1990. The primary structure of the rat guanylyl cyclase A/atrial natriuretic peptide receptor gene. $J$. Biol. Chem. 265:20414-20420.

24. Malfroy, B., P. R. Schofield, W. Kuang, P. H. Seeburg, A. J. Mason, and W. J. Hanzel. 1987. Molecular cloning and amino acid sequence of rat enkephalinase. Biochem. Biophys. Res. Commun. 144:59-66.

25. Sandberg, K., H. Ji, A. J. L. Clark, H. Shapira, and K. J. Catt. 1992. Cloning and expression of a novel angiotensin II receptor subtype. J. Biol. Chem. 267:9455-9458.

26. Sambrook, J., E. F. Fritsch, and T. Maniatis. 1989. Molecular Cloning: A Laboratory Manual, Cold Spring Harbor Laboratory, Cold Spring Harbor, NY.

27. Lander, E., P. Green, J. Abrahamson, A. Barlow, M. J. Daly, S. E. Lincoln, and L. Newburg. 1987. MAPMAKER: an interactive computer package for constructing primary genetic linkage maps of experimental and natural populations. Genomics. 1:174-181.

28. Lander, E., and D. Bostein. 1989. Mapping Mendelian factors underlying quantitative traits using RFLP linkage maps. Genetics. 121:185-199.

29. Darvasi, A., A. Weinreb, V. Minke, J. I. Weller, and M. Soller. 1993. Detecting marker-QTL linkage and estimating QTL gene effect and map location using a standard genetic map. Genetics. 134:943-951.

30. Rapp, J. P., and H. Dene. 1990. Failure of alleles at the $\mathrm{Na}^{+}, \mathrm{K}^{+}$-ATPase $\alpha_{1}$ locus to cosegregate with blood pressure in Dahl rats. J. Hypertens. 8:457462.

31. Herrera, V. L. M., and N. Ruiz-Opazo. 1990. Alteration of $\alpha 1 \mathrm{Na}^{+}, \mathrm{K}^{+}$ATPase ${ }^{86} \mathrm{Rb}$ influx by a single amino acid substitution. Science (Wash. DC). 249:1023-1026.

32. Simonet, L., E. St. Lezin, and T. W. Kurtz. 1991. Sequence analysis of the $\alpha 1 \mathrm{Na}^{+}, \mathrm{K}^{+}$-ATPase gene in the Dahl salt-sensitive rat. Hypertension (Dallas). 18:689-693.

33. Rapp, J. P., S.-M. Wang, and H. Dene. 1990. Effect of genetic background on cosegregation of renin alleles and blood pressure in Dahl rats. Am. J. Hypertens. 3:391-396.

34. Rapp, J. P., H. Dene, and A. Y. Deng. 1994. Seven renin alleles in rats and their effects on blood pressure. J. Hypertens. 12:119-125.

35. Alam, K. Y., Y. Wang, H. Dene, and J. P. Rapp. 1993. Renin gene nucleotide sequence of coding and regulatory regions in Dahl rats. Clin. Exp. Hypertens. 15:599-614.

36. Rapp, J. P., S. Y. Tan, and H. S. Margolius. 1978. Plasma mineralocorticoids, plasma renin, and urinary kallikrein in salt-sensitive and salt-resistant rats. Endocr. Res. Commun. 5:35-41.

37. Dene, H., C. McIlwain, and J. P. Rapp. 1989. Quantitation of renal renin and renin mRNA in Dahl rats in response to provocative stimuli. Clin. Exper. Hypertens. 11:1585-1594.

38. Rapp, J. P., and L. K. Dahl. 1972. Possible role of 18-hydroxy-deoxycorticosterone in hypertension. Nature (Lond.). 237:338-339.

39. Matsukawa, N., Y. Nonaka, J. Higaki, M. Nagano, H. Mikami, T. Ogihara, and M. Okamoto. 1993. Dahl's salt-resistant normotensive rat has mutations in cytochromic p450 (11 $\beta$ ), but the salt-sensitive hypertensive rat does not. J. Biol. Chem. 268:9117-9121. 